\title{
Bioprospecting Marine Microalgae for Commercial Applications
}

\section{Yogesh Pawar ${ }^{1}$, Namrata Gangal ${ }^{1}$, Yash Gupte ${ }^{1}$, Vinod Nagle ${ }^{1}$, Ajit Sapre $^{1}$, Santanu Dasgupta ${ }^{1 *}$, Ganesh Iyer $^{2}$ and Bhupal Chaugule ${ }^{3}$}

${ }^{1}$ Reliance Industries Ltd, RCP, Ghansoli, Navi Mumbai, Maharashtra, India

${ }^{2} 6$, Ganesh Co-op Society, Maharashtra, India

${ }^{3}$ BVDU Poona College of Pharmacy, Erandawane, Pune, India

*Corresponding Author: Santanu Dasgupta, Reliance Industries Ltd, RCP, Ghansoli, Navi Mumbai, Maharashtra, India.
Received: October 06, 2021

Published: November 19, 2021

(C) All rights are reserved by Reliance

Industries Ltd.

\begin{abstract}
20 marine microalgae strains from 8 genera were collected and screened for biomass generation and biochemical compositions including proteins, lipids, and carbohydrates. Fatty acid composition of extracted lipids was analyzed using GCMS to find out their uses in different industrial applications. Chlorella sp. shows the highest protein content of 52\% among the 20 strains. Highest lipid content of 29\% was observed in Dunaliella sp making it useful in the process of biofuel development. All the strains show presence of saturated fatty acids with monounsaturated fats (MUFA) are found only in 11 strains and polyunsaturated fats (PUFA) are found in 16 strains. Among PUFA $\omega-3$ and $\omega-6$ fatty acids are mostly abundant which have nutraceutical and cosmaceutical applications. Highest carbohydrate content of 70\% was found in Pseudoneochloris marina which makes it valuable for food industries.
\end{abstract}

Keywords: Microalgae; Biochemical Characterization; MUFA; PUFA; Proteins; Carbohydrates

\section{Abbreviations}

${ }^{\circ} \mathrm{F}$ : Degree Fahrenheit; $\mu \Sigma$ : Microeinstein; ASN: Artificial Seawater Nutrient; BBM: Bold's Basal Medium; GCMS: Gas Chromatography Mass Spectrometry; MUFA: Monounsaturated Fatty Acid; nm: Nanometer; OD: Optical Density; PUFA: Polyunsaturated Fatty Acid; UV: Utraviolet; $\omega$ : Omega

\section{Introduction}

Microalgae are the diverse group of unicellular algae commonly found in all habitats ranging from hot deserts to freezing temperatures. These organisms have acquired a number of characteristics to survive in the extreme environments like drought, high salinity, high temperature, high altitude, acidic environment and alkaline environment etc. Some of the algae exposed to high irradiance of sunlight have developed UV-protective substances which are useful in the cosmetic products [1]. Few algae which have experienced nutrient starvation have developed capability to store their food in the form of excess carbohydrates and lipids to survive [2]. These algae are being used in energy generation, high value products and feed products. Algae which experience extreme temperatures have evolved themselves to cope up with high and low temperatures. The study of such organisms helps us to modify agricultural crops to withstand such conditions and give consistent productivity throughout the year.

Fuel is considered as one of the major energy sources to drive any machine and consequently day-to-day life. Available source of fuel comes from fossil fuel accumulated since millions of years in the earth crust. Due to enormous fuel demand and limited supply, fossil fuel extraction has increased multiple times in past few decades [3]. Fossil fuels are non-renewable sources of energy and require tremendous amount of time and climatic favorability to form. If we get exhausted of the available fossil fuel, we will not be able to acquire the same in near future. To overcome this crisis, researchers have initiated search for alternate renewable energy source, which can be renewable. Solar and wind energy are excellent renewable alternate energy sources but cannot fulfil the power 
requirement as compared to the fossil fuel [4]. To compete with the fossil fuel in terms of strength of energy generation, search for the fuel with similar properties began which marked microalgae as a potent competitor. In the early 1950s the idea of using microalgae as biofuel arose [5]. Algae can generate different forms of renewable energy like hydrogen, alcohol, biodiesel, biomass and many more. Among these, biodiesel had been one of the most popular form. First attempt for proving effective liquid biofuel production from microalgae was made by Stanford University [6].

There are many benefits of using biofuel over fossil fuels. One of the major benefits is its renewability for production. Muhammad., et al. compared properties between biodiesel and fossil fuels to find that biodiesel has more Ctane value with greater biodegradability and non-toxicity than petroleum diesel. It has more oxygen content and contains neither any sulfur nor any aromatic compounds. Biodiesel has flash point of $300-400^{\circ} \mathrm{F}$ which is almost 3 times more than petroleum diesel and also more lubricity which makes it better fuel than petroleum diesel [7].

Several studies are reported to prove the benefits of microalgae biofuel to overcome the drawbacks of fossil fuel [8]. Few important characteristics which set microalgae apart from other biomass sources are greater yield of biomass, higher starch or oil content, non-requirement of agricultural land, nutrients supplementation by even a wastewater source and many more [9]. Microalgae have relatively higher percentage of lipids which make the process of biofuel conversion simpler. Microalgae as name suggest measure in microns as individual cells or colonies or chains in both freshwater and marine water contributing to almost half of the oxygen concentration in the atmosphere [8]. Due to scarcity of freshwater, scientists are focusing more towards marine water microalgae for non-feed applications [10].

Apart from biofuel, lipids from these marine microalgae are used in nutraceutical, pharmaceuticals and cosmetic applications. Fatty acids isolated from Isochrysis galbana have nutritive values in the animal feed formulations. Immune modulators from Lyngbya majuscule have pharmaceutical and nutritive values. DHA and EPA from different microalgal species have diverse applications in food, beverages and food supplements [11]. Among PUFA linoleic (18:2 n-6) and linolenic (18:3n-3) acids are essential fatty acids since human body cannot synthesize them. Linoleic acid has been found to regulate LDL/HDL ratio whereas linolenic acid has been observed to play a vital role in blood clotting mechanism and stabilizing the heart beats [12]. MUFA act as the filler in dietary fats [12]. Presence of MUFA in diet is found to lower LDL levels in blood but maintain HDL which are regulated by PUFA. A balance diet containing low MUFA and high PUFA ratio helps to control the lipoprotein levels. MUFA can help reduce body weight when intake calories are kept constant and MUFA intake is increased [13].

In this study we have collected, isolated, grown and characterized 20 strains of marine microalgae representing 10 genera for finding their applicability in biofuel, nutraceuticals and pharmaceuticals.

\section{Materials and Methods}

\section{Collection and isolation}

- Collection: All the strains were collected from the west coast of India covering the states of Maharashtra, Goa and Gujrat. Water samples were collected mainly from the marine and brackish water habitats. The samples were collected at different depths in the water column. For collecting the algal samples suspended in water, a phytoplankton net was tied to the boat and it was dragged through the water. Algal samples were also collected from the rocky intertidal pools, with the assumption of finding fast growing organisms that are adapted to the varying temperatures and salinity found in this habitat. All the field samples were stored in 50-100 ml collection bottles, labelled accurately at the site of collection, and kept refrigerated until they reach the laboratory.

- Isolation: All the field samples were processed for isolation. Different media like ASN III, F/2, BBM and BG 11 (with salinity of $3 \%$ ) were used for isolation. Serial dilution technique was used to carry out isolation in liquid medium in the initial stage. Subsequently the samples were plated onto agar plates to get colonies. Single algal colonies were picked up and plated onto fresh agar plates. This process was repeated until a unialgal culture was achieved. The cultures were maintained in growth racks at light intensity of $150 \mu \Sigma$. These were maintained as stock cultures with the details of their site of collection and the specific nutrient requirements.

- Morphological identification: All the strains were examined under a Leica microscope. They were divided into 
green algae, and cyanobacteria as per their pigmentation characters. After this general classification, the isolates were examined in detail for their morphological characters under the microscope and identified to the genus level using standard taxonomic methods and identification guides. Microphotographs of the algae were maintained for further reference.

\section{Growth in liquid medium}

Inoculum development: Only the unicellular green or blue green algae were taken for the experimental purpose. The strains were checked for their purity and unialgal status were confirmed. For obtaining initial inoculum, colonies from the agar plate were inoculated in triplicate in different media like ASNIII and F/2. After 7-10 days, upon establishment in these media, the cultures were subsequently inoculated into the $1.5 \mathrm{X}$ ASN III for growth. The volume was maintained at $10 \mathrm{ml}$ by ASN III media addition, and cell count/OD at $750 \mathrm{~nm}(1 \mathrm{X})$ was taken. They were incubated for 7 days, and cell count/OD at $750 \mathrm{~nm}$ was taken on alternate days. Strains showing at least $2 \mathrm{X}$ growth were selected.

\section{Screening procedure}

These selected strains were then cultured in $100 \mathrm{ml}$ flask with a total culture volume of $40 \mathrm{ml}$ in triplicate. The dilutions were done to reach a final concentration of at least $10^{6}$ cells $/ \mathrm{ml}$. They were screened for growth by monitoring cell count continuously for 7 days. The cultures were kept in an open shaker with light intensities ranging from $85 \mu \Sigma$ to $150 \mu \Sigma$.

They were monitored daily by microscopic observation for confirming the unialgal status. For counting the algal cells a Neubauer haemocytometer was used. From each flask $1 \mathrm{ml}$ sample was analyzed for cell count. Before taking actual readings, the aliquots were diluted with media to reach a dilution that gave a concentration of 25 cells/square. This ensured minimal manual errors in counting. The dilution factor was considered at the time of calculating final cell density. Five squares were chosen for counting and the average cells/square were considered for calculating the cell density.

Cell densities were calculated by following formula:

$\frac{\text { (Average number of cells per square } \times \text { Dilution factor) }}{\text { Volume of square }}=$ Cell density

Biomass estimation was done at the end of the 7 days.

\section{Scale-up procedure}

The strains showing more than $70 \mathrm{mg} / \mathrm{ml}$ biomass were categorized as fast growing strains. The cultures from the triplicate flasks were checked for their purity and then they were mixed together to get a starter inoculum for the scale up process. They cultures were inoculated in 500 and $1000 \mathrm{ml}$ flaks using ASN III media. The final step of the scale up was carried out in 5 liter bottles used for cultivation.

\section{Harvesting and drying}

To harvest biomass from liquid culture, centrifugation at 5000 rpm for 10 mins was carried out and washed with sterile distilled water twice to remove salt content. The pellet was collected and dried at $60^{\circ} \mathrm{C}$ overnight and kept in desiccator to avoid moisture in dried biomass. The dried biomass was then weighed and homogenized in mortar and pestle to obtain fine powder.

\section{Biochemical characterization}

Lipid extraction, estimation and characterization

A modified Bligh and Dyer method was employed to extract and estimate lipid content in dry algal biomass. $100 \mathrm{mg}$ of dry biomass was homogenized in minimum volume of (1:2) chloroform: methanol mixture and transferred in a separating funnel. Total volume was made to $37.5 \mathrm{ml}$ with chloroform: methanol mixture and kept for an hour with intermittent shaking. $12 \mathrm{ml}$ of Chloroform was poured and mixed vigorously. To this $10 \mathrm{ml}$ of distilled water was added and mixed thoroughly. This was allowed to stand till two clear layers were obtained. The lower chloroform layer was collected in a pre-weighed beaker and kept in water bath at $70^{\circ} \mathrm{C}$ to dry completely. The beaker with solid lipids were cooled to room temperature and reweighed to obtain the weight of lipids. The difference between the two weights was noted as \% lipid in dry biomass.

\section{Protein extraction and estimation}

Protein extraction protocol was followed as suggested by Barbarino and Lourenco in 2005. The estimation was followed as per the protocol of Folin-Lowry [14]. The estimation of proteins was calculated by plotting values on standard BSA graph.

\section{Carbohydrate extraction and estimation}

$100 \mathrm{mg}$ of dried biomass was homogenized in $2 \mathrm{ml}$ of $2.5 \mathrm{~N} \mathrm{HCl}$ and transferred in a test tube. $3 \mathrm{ml}$ of $2.5 \mathrm{~N} \mathrm{HCl}$ was added to make total of $5 \mathrm{ml}$. The tubes were then placed in boiling water bath for 3 
hours and cooled at room temperature. The content was decanted in a $150 \mathrm{ml}$ glass beaker. Crystals of sodium carbonate was added to it till neutralized. The solution was diluted till $100 \mathrm{ml}$ using distilled water and $1 \mathrm{ml}$ of it was used for estimation. Phenol sulfuric acid method was employed for estimation of carbohydrates [15]. Absorbance values were plotted on standard glucose graph to estimate the percent concentration of carbohydrates.

\section{Determination of ash content}

$100 \mathrm{mg}$ of dry biomass was weighed in a pre-weighed crucible and kept in furnace at $700{ }^{\circ} \mathrm{C}$ for an hour. The crucible was cooled at room temperature and weighed again to get the weight of ash. This was reported as percent ash in dry biomass.

\section{Gas chromatography mass spectroscopy (GCMS) of lipids}

Extracted algal lipids were esterified to fatty acid methyl esters (FAME) through methanolic esterification and profiled using GCMS (Schlechtriem, Henderson, and Tocher, 2008). Esterified fatty acids were separated using hexane. Hexane was evaporated and fatty acids were dissolved in Chloroform. $10 \mu \mathrm{l}$ of this fatty acid solution was injected into Shimazdu GC-MS-QP2010 Ultra with Restek FAME-WAX column having length of 100 meters. The Total flow was set at $24.5 \mathrm{ml} / \mathrm{min}$, Column flow was kept at $3.59 \mathrm{ml} / \mathrm{min}$, linear velocity at 70.4 and purge flow at 3.0. Temperature ramping was set as shown in table 1 . The run time was set at 50 mins with carrier gas as Helium.

\begin{tabular}{|l|c|c|c|}
\hline $\begin{array}{l}\text { Start Temperature } \\
\left({ }^{\circ} \mathbf{C}\right)\end{array}$ & $\begin{array}{c}{ }^{\circ} \mathbf{C} \text { per min } \\
\text { rise }\end{array}$ & $\begin{array}{c}\text { Final Temperature } \\
\left({ }^{\circ} \mathbf{C}\right)\end{array}$ & $\begin{array}{c}\text { Hold time } \\
(\mathbf{m i n s})\end{array}$ \\
\hline 100 & 10 & 180 & 0 \\
\hline 180 & 2 & 215 & 0 \\
\hline 215 & 0 & 215 & 25 \\
\hline
\end{tabular}

Table 1: Temperature ramping in GCMS for Fatty acid analysis.

\section{Results and Discussion}

\section{Collection and isolation}

This study focusses mainly on screening of algae for the purpose of their commercial applications in fuel and food industry. Algae are photosynthetic microorganisms whose growth is dependent on many factors like light, temperature, $\mathrm{pH}$, amount and availability of nutrients and $\mathrm{CO}_{2}$. The environmental conditions also play a pivotal role in the adaptation and growth of the microalgae species found in a particular region. Hence, locally isolated strains are best suited and adapted for outdoor cultivation at a commercial scale. In order to find the right candidate for the biofuel production it is critical to isolate and screen a substantial amount of strains followed by their characterization for growth and productivity. It is only after this we can get the ideal candidates displaying a high growth rate, productivity, and a high lipid content [16].

All the strains used in this study were isolated from the west coast of India. The sampling was mainly done from the marine and brackish water habitats. The water samples were collected from the surface and the middle zones of the water bodies, with the objective of finding the most dominant species in that area. Sampling in the intertidal zone wherein the ecosystem is dynamic ensured the collection of the species with high growth rate.

\section{Strain isolation}

In order to obtain a unicellular microalgal cultures the field samples were subjected to standard methods of isolation like serial dilution technique. The field samples were concentrated and subjected to various enrichment media. A number of different media were used for isolation in the initial stage in order to get maximum number of species. After serial dilution, standard plating techniques were employed in order to get unicellular colonies. At the end of the entire procedure, 20 microalga species belonging to 8 different genera were isolated. Table 2 gives the list of genera and detail list of species given in table 3 . The most abundant genera were Chlorella and Nannochloropsis followed by Dunaliella and Picochlorum.

\begin{tabular}{|l|c|}
\hline Sr no & Genus \\
\hline 1 & Chlorella \\
\hline 2 & Dunaliella \\
\hline 3 & Tetraselmis \\
\hline 4 & Cyanobacterium \\
\hline 5 & Nannochloropsis \\
\hline 6 & Nannochloris \\
\hline 7 & Picochlorum \\
\hline 8 & Pseudoneochoris \\
\hline
\end{tabular}

Table 2: List of genera collected and isolated.

\section{Growth in liquid medium}

All the strains that were isolated were scaled up in the ASN III commercial media. Here all the provided nutrients are in excess $(1.5 \mathrm{X})$ as compared to the other common media ASN III and F/2 


\begin{tabular}{|c|c|c|c|}
\hline $\begin{array}{l}\text { Strain } \\
\text { number }\end{array}$ & Organism & $\begin{array}{c}\text { Strain } \\
\text { number }\end{array}$ & Organism \\
\hline 1 & Chlorella sp_1 & 11 & $\begin{array}{c}\text { Nannochloropsis } \\
\text { sp_1 }\end{array}$ \\
\hline 2 & Chlorella sp_2 & 12 & $\begin{array}{c}\text { Nannochloropsis } \\
\text { sp_2 }\end{array}$ \\
\hline 3 & Chlorella sp_3 & 13 & $\begin{array}{c}\text { Nannochloropsis } \\
\text { sp_3 }\end{array}$ \\
\hline 4 & $\begin{array}{l}\text { Chlorella } \\
\text { vulgaris }\end{array}$ & 14 & Nannochloris sp_1 \\
\hline 5 & $\begin{array}{c}\text { Chlorella } \\
\text { sorokiniana }\end{array}$ & 15 & Nannochloris sp_2 \\
\hline 6 & Dunaliella sp_1 & 16 & Picochlorum sp_1 \\
\hline 7 & Dunaliella sp_2 & 17 & Picochlorum sp_2 \\
\hline 8 & Dunaliella sp_3 & 18 & Picochlorum sp_3 \\
\hline 9 & Tetraselmis sp & 19 & $\begin{array}{c}\text { Pseudoneochloris } \\
\text { marina }\end{array}$ \\
\hline 10 & $\begin{array}{c}\text { Nannochloropsis } \\
\text { oceanica }\end{array}$ & 20 & $\begin{array}{c}\text { Cyanobacterium } \\
\text { aponinum }\end{array}$ \\
\hline
\end{tabular}

Table 3: List of the RIL strains used in the study.

media. The logic behind this approach was that the strains should not struggle for any of the nutrients during their growth phase. Factors regulating the qualitative and quantitative properties of biomass and FAMEs in microalgae are nutrients $[17,18]$. The requirements of nutrients of algae belonging to different classes and family vary. An important criterion for assessing the growth of microalgae is optical density, which helps to understand the growth cycle of algae including the lag, log or the exponential and the stationary phase. Graphical representation of the optical density and growth data is visible in figure 1 . Here, we can see the optical density plot for the different strains studied. Nannochloropsis followed by Dunaliella and Chlorella displayed the highest growth rate. The biomass productivity was also the highest in Nannochloropsis followed by Chlorella and Dunaliella.

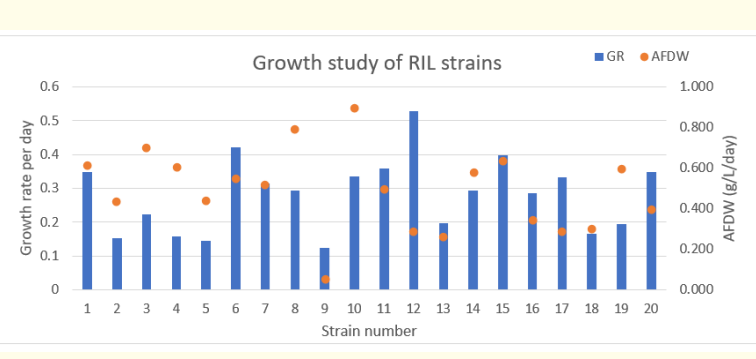

Figure 1: Growth Performance of RIL strains.
Scale-up procedure

Growing microalgae can have numerous advantages over any other conventional forms of biomass as they do not require land for cultivation and are able to grow in brackish, marine or wastewater. In addition to their use as a biofuel, they have opportunities in food, protein products, aqua feed, cosmetic and several other commercially viable products. Thus, algal biomass is of great value. However, in order to make this process commercially viable they should be cultivated at higher cell densities and in open outdoor conditions [19]. This needs the selection of a robust strain and proper scale up thereafter. During our study, we have screened different algal species and selected the few displaying higher growth rates and biomass. Scale up process started from single cell colony to conical flasks and further scale up in 5-liter growth bottles under controlled laboratory conditions. In order to attain maximum biomass production, outdoor cultivation can be practiced. Two third of earth's surface is covered with oceans, so cultivation of marine algae could bring a new opportunity in food, pharmaceutical industries and also help to mitigate the ever increasing global energy needs.

\section{Harvesting and drying}

$100 \%$ biomass was harvested using centrifugation and the supernatant is reused for cultivating fresh batch of the strain. Washing with sterile distilled water removed almost $95-99 \%$ of salt content. Drying at $60{ }^{\circ} \mathrm{C}$ overnight ensures no change in the biochemical components and removes most of the moisture.

\section{Biochemical characterization}

As per the results of lipids, proteins and carbohydrates contents in RIL strains (Figure 2), maximum lipid content of $29.17 \pm 0.82 \%$ was found in Dunaliella sp_3 followed by Dunaliella sp_2, Nannochloropsis $s p \_2$, Dunaliella sp_1 and Cyanobacterium aponinum with $28.33 \pm 1.73 \%, 25.29 \pm 0.94 \%, 25 \pm 0.93 \%, 24.67 \pm 0.96 \%$ respectively. These high lipid strains are suitable for biofuel production purpose whereas strains with high protein content can be utilized as single cell protein products. High protein containing strains are Chlorella sp._1 containing 52.61\%, followed by Picochlorum sp_2, Nannochloris sp._1, Chlorella sp._2 and Chlorella vulgaris with 48.21 $\pm 2.22 \%, 43.06 \pm 1.16 \%, 42.72 \pm 1.2 \%$ and $40.94 \pm 1.27 \%$ respectively. Those strains with high carbohydrate content are suitable for poultry feed and aqua feed applications. Pseudoneochloris sp. shows the highest carbohydrate content of $70.42 \pm 4.79 \%$ followed by Picochlorum sp_3, Nannochloropsis oceanica and Chlorella sp_2 with $57.69 \pm 5.31 \%, 53.68 \pm 3.11 \%, 53.33 \pm 2.67 \%$ respectively. 
It is observed that Dunaliella $s p$ are preferred for biofuel production due to their high average lipid content of $27.5 \pm 2.2 \%$ which is highest among the studied genera. The genus is also has a good protein content of $31.15 \pm 6.8 \%$ with reserve food carbohydrate content of $35.69 \pm 9.6 \%$ The results support the analysis performed by Muhaemin and Kaswadji on Dunaliella salina in 2010. This genus can be used in all the areas including biofuel, feed and protein applications.

The genus Chlorella is worldwide known for its protein content as single cell protein. In our study we also found the average highest protein content in Chlorella with $42.9 \pm 9.6 \%$. Low lipid content of $8.38 \pm 3 \%$ and high carbohydrate content of $45 \pm 7.4 \%$ confirms the primary food reserve as carbohydrates. The similar results are found in Picochlorum with average protein, lipid and carbohydrate content of $31.61,18.66$ and $42.6 \%$ respectively. These strains are thus found to be useful in the protein food and feed applications. The high carbohydrate content of these algae can replace the conventional carbohydrate sources from fish feed and poultry feed and provide proteins, secondary metabolites like antioxidants in addition to carbohydrates.

High carbohydrate containing microalgae such as Pseudoneochloris marina in the current study, are used in the preparation of many food products. Extracted carbohydrates can be utilized into fermenting breads, ready to make soups, sauces, variety of bakery products etc. These carbohydrate molecules are also widely used in bioplastic production, sugars, agar, alcohols like butanol, organic acids such as succinic acids and lactic acids and many high value products $[20,21]$.

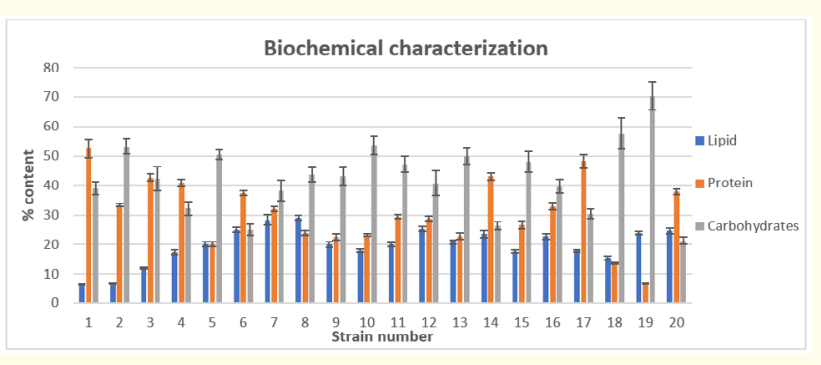

Figure 2: Lipid, protein and carbohydrate contents in RIL strains.

\section{GCMS profiling of FAME}

For the ease of analysis GCMS profiles of RIL strains are depicted in two major groups, saturated and unsaturated fatty acids.
Unsaturated fatty acids are further segregated into two subgroups, monounsaturated (MUFA) and polyunsaturated (PUFA) fatty acids. Majority of the strains show dominance of saturated fatty acids. 11 strains show presence of MUFA and 16 strains show presence of PUFA. 9 strains out of 20 show presence of all the three groups of fatty acids. MUFA have a number of health benefits that include help in weight loss process, reducing risk associated with heart diseases by decreasing bad cholesterol levels and decreasing inflammation [22]. PUFA have great applications in the biofuel formation and also in treating diseases like Alzheimer, Parkinson and Atherosclerosis [23].

Chlorella sp. have lipids rich in saturated fatty acids. Of the total, C16 fatty acids were $15-40 \%$ and C18 fatty acids were $20-60 \%$, C20 and C13 fatty acids were present in one Chlorella sp. Cyanobacterium aponinum strain had 27\% C16 fatty acids, 12\% C18 fatty acids, $15 \%$ C14 fatty acids. Dunaliella sp. had 13-55\% C16 fatty acids and 30-60\% C18 fatty acids. Nannochloropsis sp. had 20-50\% C16 fatty acids and 20-60\% of C18 fatty acids. Nannochloris sp., Picochlorum sp. and Psuedoneochloris sp. each had 40-50\% of each C16 and C18 fatty acids. Tetraselmis sp. had 30\% C16 fatty acids and 40\% C18 fatty acids. Nannochloropsis oceanica contains PUFA linoleic acid, eicosapentanoic acid [EPA] and arachidonic acid which are major contributors of fish feed [24].

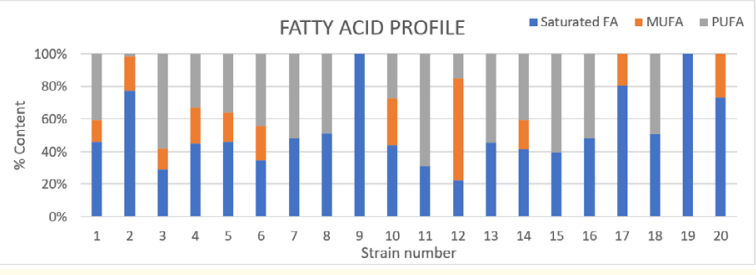

Figure 3: Fatty acid profiles in RIL algae strains.

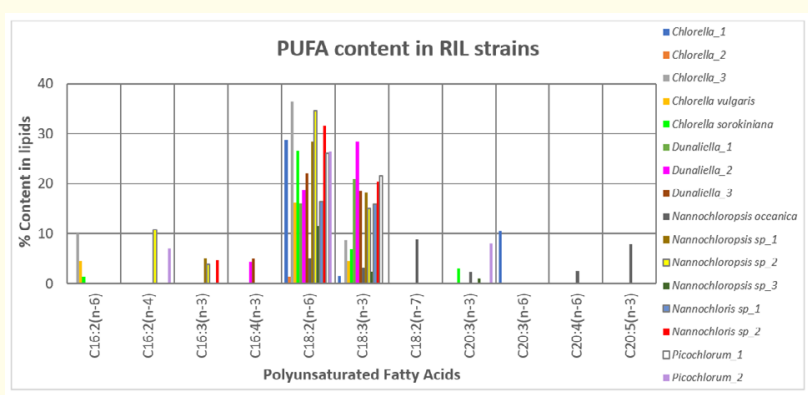

Figure 4: Characterization of Polyunsaturated Fatty Acids (PUFA) in RIL algal strains. 
The most occurring PUFA in the RIL algae is linoleic acid C18:2(n-6), a $\omega 6$ fatty acid, which is extensively applied in the cosmetics and personal care products to keep the skin moisturized [25]. Linolenic acid C18:3(n-3), a $\omega 3$ fatty acid, is second dominant fatty acid in most of the algal strains. $\omega 3$ are known to decrease Attention Deficit Hyperactivity Disorder [26], anxiety, depression $[27,28]$ etc.

The data presented in the manuscript is based describes the strain characteristic related to growth and biochemical composition in standard growth medium. The genera Nannochloropsis followed by Dunaliella and Chlorella are the fastest growing among others with Nannochlorpsis showing growth rate of 0.52 per day which is higher than the reported values of 0.11 to 0.21 per day [29]. Highest protein content of 52.61\% was observed in Chlorella sp. which is comparable to the reported values of $42-58 \%[30,31]$. PUFA content of RIL Chlorella ranges between 25-55\% which is comparable or slightly higher than the published values [32]. PUFA content of Nannochloropsis ranges between 14-65\% which is in parallel to the published data [33]. Indian marine algal strains have high biochemical contents as compared to other strains and hence can be utilized in most of the commercial processes like biofuel, aqua feed, cosmetics, nutraceuticals etc.

\section{Conclusion}

RIL algae strains were screened for their biochemical parameters and showed a great results in terms of diverse applicability. The genus Chlorella and Picochlorum are suitable for single cell protein applications in the nutraceutical food supplements. MUFA and PUFA contents in the most of the strains suggest their health benefits exploring therapeutic applications. $\omega-3$ and $\omega-6$ fatty acids from these strains can be utilized in the nutraceutical and cosmaceutical applications. Strains with high carbohydrate content can directly be used in developing sustainable products including bioplastics which can replace the traditional non-degradable plastic material. Microalgae application in the industrial processes have an added benefit of $\mathrm{CO} 2$ sequestration which is now-a-days a high demand for environmental sustainability.

\section{Acknowledgement}

We acknowledge the RIL management for funding the work carried out in the current research.

\section{Conflict of Interest}

Author declares no conflict of interest.
Bibliography

1. Pangestuti R., et al. "Photoprotective Substances Derived from Marine Algae”. Marine drugs 16.11 (2018): 399.

2. Zhu L D., et al. "Strategies for Lipid Production Improvement in Microalgae as a Biodiesel Feedstock". BioMed Research International (2016): Article ID 8792548.

3. Manieniyan V., et al. "Study on energy crisis and the future of fossil fuels". Proceedings of SHEE 2009. (2009).

4. Capellán-Pérez Iñigo., et al. "Fossil Fuel Depletion and SocioEconomic Scenarios: An Integrated Approach”. Energy (2014).

5. Allaboutalgae.com. n.d. Algae Biomass Organization.

6. Rahman Nadiv. "Biofuels From Microalgae: A Viable Option for the Future". Stanford University (2013).

7. Muhammad Usman Lawan., et al. "Biofuels as the Starring Substitute to Fossil Fuels". Petroleum Science and Engineering 2.1 (2018): 44-49.

8. Bošnjaković Mladen. "Biodiesel from Algae". Journal of Mechanics Engineering and Automation 3 (2013): 179-188.

9. Van Ierse Sjors., et al. "Algae Based Biofuels: A Review of Challenges and Opportunities for Developing Countries". United Nations: Food and Agriculture Organization (2009).

10. Stolark Jessie. "Marine Microalgae: the Future of Sustainable Biofuel". 08 February (2017).

11. Joshi Nilesh Hemantkumar and Ilza Rahimbhai Mor. "Microalgae and Its Use in Nutraceuticals and Food Supplements". Microalgae - From Physiology to Application. Milada Vítová, IntechOpen (2019).

12. Hayes KC DVM. "Dietary fat and heart health: in search of the ideal fat". Asia Pacific Journal of Clinical Nutrition 11 (2002): S394-S400.

13. Walker KZ., et al. "Dietary composition, body weight, and NIDDM. Comparison of high-fiber, high-carbohydrate, and modified-fat diets". Diabetes Care 18.3 (1995): 401-403.

14. Lowry O H., et al. "Protein measurement with Folin Phenol Reagent". Journal of Biological Chemistry 193 (1951): 265275.

15. DuBois M., et al. "Colorimetric Method for Determination of Sugars and Related Substances". Annals of Chemistry 28.3 (1956): 350-356. 
16. Lee K., et al. "Isolation and screening of microalgae from natural habitats in the Midwestern United States of America for biomass and biodiesel sources". Journal of Natural Science, Biology and Medicine 5.2 (2014): 333-339.

17. Converti Attilio., et al. "Effect of temperature and nitrogen concentration on the growth and lipid content of Nannochloropsis oculata and Chlorella vulgaris for biodiesel production". Chemical Engineering and Processing: Process Intensification 48.6 (2009): 1146-1151.

18. Liang Y., et al. "Biomass and lipid productivities of Chlorella vulgaris under autotrophic, heterotrophic and mixotrophic growth conditions". Biotechnology Letter 31 (2009): 10431049.

19. Rathinam Raja., et al. "Biomass from Microalgae: An Overview". Journal of Oceanography and Marine Research 2.1 (2014): 1-7.

20. Maiara Priscilla de Souza., et al. "Concepts and Trends for Extraction and Application of Microalgae Carbohydrates". Microalgae - From Physiology to Application, Milada Vítová, IntechOpen (2019): 1-13.

21. M Teresa Cesário., et al. "Marine algal carbohydrates as carbon sources for the production of biochemicals and biomaterials". Biotechnology Advances 36.3 (2018): 798-817.

22. Schwingshackl Lukas and Georg Hoffmann. "Monounsaturated Fatty Acids and Risk of Cardiovascular Disease: Synopsis of the Evidence Available from Systematic Reviews and MetaAnalyses". Nutrients 4.12 (2012): 1989-2007.

23. Hossein Alishah Aratboni., et al. "Biomass and lipid induction strategies in microalgae for biofuel production and other applications". Microbial Cell Factories 18 (2019): 178.

24. González-Félix M., et al. "Nutritional evaluation of fatty acids for the open thelycum shrimp, Litopenaeus vannamei: II. Effect of dietary n-3 and n-6 polyunsaturated and highly unsaturated fatty acids on juvenile shrimp growth, survival, and fatty acid composition". Aquaculture Nutrition 9 (2003): 115-122.

25. Ida I Muhamad., et al. "Chapter 14 - Extraction Technologies and Solvents of Phytocompounds From Plant Materials: Physicochemical Characterization and Identification of Ingredients and Bioactive Compounds From Plant Extract Using Various Instrumentations". Alexandru Mihai Grumezescu, Alina Maria Holban. Ingredients Extraction by Physicochemical Methods in Food A volume in Handbook of Food Bioengineering. Academic Press (2017): 523-560.
26. Königs A and AJ Kiliaan. "Critical appraisal of omega-3 fatty acids in attention-deficit/hyperactivity disorder treatment". Neuropsychiatric Disease and Treatment 12 (2016): 18691882.

27. Wani A L., et al. "Omega-3 fatty acids and the treatment of depression: a review of scientific evidence". Integrative Medicine Research 4.3 (2015): 132-141.

28. Larrieu T and Layé S. "Food for Mood: Relevance of Nutritional Omega-3 Fatty Acids for Depression and Anxiety". Frontiers in Physiology 9 (2018): 1047.

29. Xiao-Nian Ma., et al. "Lipid Production from Nannochloropsis". Marine Drugs 14 (2016): 61.

30. Enyidi Uchechukwu D. "Chlorella vulgaris as Protein Source in the Diets of African Catfish Clarias gariepinus". Fishes 2 (2017): 17.

31. Reen Chia Shir., et al. "Microalgal Protein Extraction From Chlorella vulgaris FSP-E Using Triphasic Partitioning Technique With Sonication". Frontiers in Bioengineering and Biotechnology 7 (2019): 396.

32. Freitas Hércules Rezende. "Chlorella vulgaris as a Source of Essential Fatty Acids and Micronutrients: A Brief Commentary". The Open Plant Science Journal 11 (2019).

33. Krienitz Lothar and Manfred Wirth. "The high content of polyunsaturated fatty acids in Nannochloropsis limnetica (Eustigmatophyceae) and its implication for food web interactions, freshwater aquaculture and biotechnology". Limnologica 36.3 (2006): 204-210.

34. Thomas W H., et al. "Screening for Lipid Yielding Microalgae: Activities for 1983". Final Subcontract Report. Solar Energy Research Institute. Colorado: SERI (1984).

35. Muhaemin Moh and DRF Kaswadji. "Biomass Nutrient Profiles of Marine Microalgae Dunaliella salina". Jurnal Penelitian Sains 13.3D (2010): 64-67.

36. Barbarino E and S O Lourenco. "An evaluation of methods for extraction and quantification of protein from marine macroand microalgae". Journal of Applied Phycology 17 (2005): 447-460.

\section{Volume 4 Issue 12 December 2021 (C) All rights are reserved by Reliance Industries Ltd.}

